\title{
Development and Underdevelopment in Britain and Ireland
}

\section{Martin Minogue}

Many people, covering many academic disciplines, have an interest in what they would refer to as development, and approach it from the direction of what they conceive to be underdevelopment. This type of labelling customarily follows on from some narrower interest; either in a particular region (for example Africa, Asia, Latin America); or in a particular place (e.g. Nigeria, Brazil, China); or in particular peoples and cultures (e.g. the Ik-speaking peoples). Some people, particularly economists and political scientists, start from the theoretical end of the spectrum: their interest in particular regions, economics, political systems and so on derives from their hope that the material they find there will enable them to construct tighter theoretical formulations of their discipline. In either case, empirical interest in development is addressed firmly to societies which by relatively crude but clear criteria can be sharply distinguished from modern, industrial nations-and that invariably means a distinction between non-Western and Western nations. This distinction, potentially a patronising one, has been expressed in a variety of terms: developed-underdeveloped, developed-less developed, advanced-backward, rich-poor, high incomelow income-and so on. Often, the way the dichotomy is expressed reveals the user's conception of development as a linear one, embedded in implicit or explicit values about what sort of development is desirable.

A closer look at the reality of both parts of the dichotomy shows how unsatisfactory this sort of terminology is. It oversimplifies, for instance, the reality of so-called 'rich' states: that they invariably have significant numbers of relatively deprived people living in areas which are also relatively deprived. It also oversimplifies the reality of 'poor' states; that they have significant pockets of wealth and privilege, and that some peoples or regions are relatively better off than other peoples or regions in the same national system. The concept of relative deprivation would perhaps be more flexible than current modes of thought about development and underdevelopment, and would avoid present difficulties of where to place societies on the development-underdevelopment spectrum. It should also allow those in
Western societies who are interested in the structures and characteristics of 'underdevelopment' (or relative deprivation) more easily to pursue their interests, once it is acknowledged that the characteristic problems of development can be analysed by reference to their own societies. A considerable obstacle to the refinement and 'testing' of developmental theories-in any disciplinary area-is presented by the inclement research climate in the great majority of the 'new' states; and that research climate seems unlikely to improve very quickly. If a researcher can, then, legitimately turn to more accessible societies (with the additional advantage that he may understand them better anyway) he is just as likely to produce material, hypotheses, even theories, which could advance our understanding of the phenomena of social, economic, and political change. Whether he can do this legitimately will depend on two things : first, whether the conceptual framework for empirical studies is rigorous, and second, whether other people in the 'development field' accept that the study of development does not of necessity focus only on non-industrial societies, and that such a focus has become a matter of habit rather than logic.

In these terms, I believe that studies of 'development' in Britain (and Ireland) are not only of intrinsic interest, but can make a contribution to the existing body of knowledge about development and underdevelopment in general. There is no doubt of the existence of deprived areas and deprived people in our societies; no serious doubt about the existence of quite major inequalities in the distribution and enjoyment of the social and economic benefits created by these societies; and no shortage of material for the analysis of these problems. There is already substantial economic analysis of differential regional development both in Britain and in Ireland, but rather less analysis of social and political disparities (though there is certainly considerable practical political interest at present in the existence of marked regional identities). There is considerable material here too for anyone with an interest in public policy, because in both countries there are positive government policies in relation to clearly stated 'developmental' objectives. Administrative and political means have been provided for the realisation of these devel- 
opmental policies. The crucial questions are still to be answered by research: what does 'development' mean in detail in these societies? How cogently, and by whom, have policies been formulated? How effective is the administrative machinery created to implement and administer these policies? What sort of impact has development policy had on the structure of deprived areas (and their relationships within the national network of social and economic structures)? And, crucially, upon the life-experiences and lifechances of deprived people living in these deprived areas? These are questions which largely remain to be answered in both Britain and Ireland.

\section{Ireland}

Ireland has some claim to be regarded as more comparable with new and developing states than with Britain. It shares with most of them a colonial history, which has left a substantial legacy of political bitterness and distrust and the continuing problem of Ulster. It is a relatively new state. It has suffered, as have other former colonies, considerable economic and social exploitation at British hands. The principal industry is agriculture, accounting for about one-fifth of the national income, almost 60 per cent of total exports, and employing almost 30 per cent of the working population (60 per cent in the West of Ireland). The industrial sector shows rapid expansion over the past 20 years, an expansion planned and supported by the government. But unemployment and under-employment remain high, and there is substantial overseas migration of labour though this is offset by a high rate of population increase. A government report in 1958 suggested that "a great and sustained effort" was necessary "to avoid economic decadence".

But in other ways, Ireland is directly comparable with Britain. On most indicators, the general standard of living in Ireland is more comparable with standards in rich industrial states than with poor agricultural states. Ireland has working democratic institutions, and an administrativepolitical system which has provided for at least basic social needs. There is a prosperous managerial/professional/business class. Urban culture is broadly similar to that of Britain. The Irish economy is linked closely to the British economy. To an observer from Mars, or Mauritius, Britain and Ireland would seem indistinguishable.

Moreover, 'development' in Ireland has a history which begins with the English, and the early approaches to development have left their mark on present arrangements. For example, the English had machinery for the encouragement and supervision of land improvement at the end of the nineteenth century, and the current version (the Irish Land Commission) is scarcely more effective now than it was then in its impact on the system of land tenure. Again, early in this century, the West of Ireland was regarded as having special problems of deprivation, and the Congested Districts Board was the spiritual forerunner of the very recently created Western Development Board. The principal governmental agency for local development is still the local authority, reflecting a strong historical British value. In its type of chief executive (the County Manager) it has a central focus of policy-making influence and executive authority combined, which is a potentially sharp organisational instrument. But, largely unreformed, it is a creaking vehicle for the administration of development, and as T. J. Barrington puts it, "It is not a system, it is not local, and it is not self-government".

The poorest area in Ireland is the West Region, comprising the counties of Galway and Mayo (one of nine planning regions, the delineation of which, according to Helen O'Neill "appears to have had all the precision normally associated with the business of pinning the tail on the donkey"). The case of Galway County demonstrates the 'institutional indigestion' associated with the administration of development policies in Ireland. The Galway authority incorporates a County Development Team which has the task of co-ordinating all 'development' activities in the county (essentially the job is done by two men; the County Manager and the County Development Officer). The county has statutory responsibilities for physical planning and development, roads, housing, and water supplies. It has advisory, coordinating, or agency responsibilities of one kind or another in relation to the Industrial Development Authority (which has planning region boundaries) the Irish Tourist Board (Bord Failte, also with West Region boundaries), numerous other state-sponsored bodies, the county committee of agriculture, a statutory health board (with regional boundaries which add Roscommon to Galway and Mayo), some other central departments, and a large number of voluntary organisations. An additional complication is provided by the Irish-speaking area, the Gaeltacht which falls partly within the county boundaries but is constituted as a separate planning region and is under the overall control of a special statutory body.

This criss-crossing of lines of action, responsibility, and advice (Desmond Roche refers to a "chaos of regional improvisations") is a formula for no more than sporadic realisation of developmental goals; but the avoidance of clear-cut 
machinery for control and implementation of development plans was quite deliberately proclaimed as a positive policy in the first development plan (the First Programme for Economic Expansion) in 1958: "the aim is not to draw up a detailed five or 10 year plan of national development ... planning in a rigid sense is not useful in our circumstances (but) one may reasonably hope to find some guiding principles which it would be advantageous to follow through thick and thin". An uneasy sense of how much was being left to chance here probably explains a later remark tinged with predictive apprehension: "a target is an aim, not a promise". And 10 years" experience produced the unsurprising comment in a government review of the second development plan (Second Programme for Economic Expansion): "implementation is the most important single aspect of an economic plan, and one to which insufficient attention was devoted in the Second Programme." A Third Programme consolidated the reorganisation of the county development teams begun in 1965, but the basic problem of administrative action lay in the defective local authorities, and the division of planning responsibilities between many different agencies, public and voluntary.

A significant factor in the West, and especially in the Gaeltacht, is the personalist nature of Irish political life. This has generally been regarded as a weakness, in that Irish people in their relations with the administrative system prefer to use political intermediaries rather than recognised organisational channels and procedures. But it has been suggested, on the contrary, that development planning has failed to take advantage of the symbiotic relationship between local politicians and local communities, relying instead on organisational mechanisms less fitted to attract local cooperation. As a result of these and other factors, there is a feeling in Ireland that planning for development, though enjoying some notable successes (the Shannon Free Airport Development scheme, for example, though even this is castigated by the economist Helen O'Neill in her study of economic planning in Ireland, as "a foreign enclave within the Irish economy"), has not made sufficient impact on the incidence of inequality in Ireland, and in particular in the poorest areas: "on the whole one can safely say that, despite all this administrative activity, the West has not yet been saved" (T. J. Barrington). Economic policy has been sharply criticised for its preoccupation with a strategy of urban growth and industrial expansion, while neglecting a complementary rural strategy involving reorganisation of the agrarian sector. It must be hoped that the recent creation of a Western Development Board is more than another administrative solution to a body of development problems with significant social and political structural features.

\section{Britain}

Lack of space prevents more than the briefest outline. Strategies and institutional arrangements for regional development in England have many similarities with the Irish situation. First, recognition of the existence of disadvantaged areas, and policies addressed to their problems, are of long standing (the Development Commission, now to be restricted to England instead of the whole of Britain, was first set up in 1909/10). Second, as in Ireland, there is a disinclination to grasp firmly the nettle of regional development strategy. Instead of a coherent set of guidelines, there is a welter of policies, agencies (public and private) and jurisdictions. Except in Scotland and Wales, executive powers lie mainly with local authorities, central departments, and public enterprises. Even in Scotland and Wales, where Development Agencies were recently created (on the explicit grounds that one cohesive agency was better than numerous conflicting jurisdictions and interests), many initiatives will depend on the collaboration of local authorities. On closer analysis the principal focus of the 'development' activities of these agencies is on industrial promotion, with a preference for light industries and tourism as the solution to the problem of job creation in declining areas. Little coherent thought appears to be given to the social impact of industrial development or the essential inter-relationship of agricultural and industrial strategies. Indeed, we must turn to the (English) Development Commission for a positive set of ideas about the social consequences of rural decline and depopulation, though the diversity of statutory and voluntary organisations involved (in a quite piecemeal fashion) in the realisation of these ideas gives the researcher considerable pause for thought.

The intention of this note is to indicate, albeit briefly and inadequately, the range of interest open to the student of development on our own doorstep. The diverse activities of the Development Commission, the Highlands and Islands Board, the Welsh Development Agency, the Gaeltacht and Irish local authorities are fascinating enough in themselves; but their wider claim to attention is that they are involved in attempts to resolve conditions of underdevelopment which in kind are not to be distinguished from the condition of underdevelopment anywhere in the world. 